Article

\title{
Enhanced Adsorption of Organic Compounds over an Activated Carbon Cloth by an External-Applied Electric Field
}

\author{
Mattia Pierpaoli *, Maria Letizia Ruello and Gabriele Fava \\ Department of Materials, Environmental Sciences and Urban Planning, Università Politecnica delle Marche, \\ Via Brecce Bianche 12, Ancona 60131, Italy; m.l.ruello@univpm.it (M.L.R.); g.fava@univpm.it (G.F.) \\ * Correspondence: m.pierpaoli@pm.univpm.it; Tel.: +39-071-220-4414
}

Academic Editor: Zhongchao Tan

Received: 1 March 2017; Accepted: 10 April 2017; Published: 12 April 2017

\begin{abstract}
Adsorption of pollutants on activated carbon is an effective air pollution control technique. In this study, a strong and non-uniform electric field was applied over an activated carbon fiber cloth. The adsorption kinetic of several organic compounds (Acetone, Acetaldehyde, Benzene, Cyclohexane, Ethanol, Methyl Ethyl Ketone, Toluene, 1-Propanol) on the activated carbon cloth was evaluated in the presence and in the absence of an electric field. Results suggest that its application enhances the adsorptive process. A linear correlation was found between such enhancement and the specific heat of liquefaction of the organic compounds.
\end{abstract}

Keywords: air pollution control; activated carbon; electric field; organic compounds; enhanced adsorption

\section{Introduction}

The adsorption on activated carbon is considered to be one of the most effective methods for the removal of pollutants from the air. Activated carbon cloth is widely used because it is easily implementable and commercially available. As the activated carbon production, regeneration and disposal costs can be a limiting factor for big scale applications, it is desirable to optimize the adsorptive process.

The use of non-thermal plasma induced by dielectric corona discharge is reported by many authors to be an effective way to oxidize many Volatile Organic Compounds (VOCs), both by coupling with a catalyst [1,2] or by use on its own [3]. However, the application of a sufficiently high voltage to a thin electrode immersed in air can lead to the creation of reactive species [4,5], which are moved by the Coulomb force [6].

Air consists of a mixture of oxygen $\left(\mathrm{O}_{2}\right)$ and nitrogen $\left(\mathrm{N}_{2}\right)$. When air is overstressed electrically, the oxygen molecule is split up into $\mathrm{O}$ and it becomes very chemically reactive [7]. Electron-impact reactions mainly occur in the corona plasma region. However, produced radicals may be transported outside of the corona plasma region.

The atoms can combine into $\mathrm{O}_{2}$ or ozone, and if the electrical stress is very high, the oxygen enters chemical combination with the nitrogen, forming nitrogen oxides.

An exhaustive list of reaction mechanisms for ozone and nitrogen oxides production in positive corona discharges has been compiled by Chen et al. [4] but, by way of simplification, we can summarize the overall reaction in several steps: the initial step in formation of $\mathrm{O}_{3}$ and $\mathrm{NO}_{\mathrm{x}}$ is given by the dissociation of molecular $\mathrm{O}_{2}$ and $\mathrm{N}_{2}$ by electron impact: 


$$
\begin{aligned}
& e+\mathrm{O}_{2} \rightarrow \mathrm{O}+\mathrm{O}+e \\
& e+\mathrm{N}_{2} \rightarrow \mathrm{N}+\mathrm{N}+e
\end{aligned}
$$

atomic nitrogen reacts with $\mathrm{O}_{2}$ and $\mathrm{O}_{3}$ to form NO:

$$
\begin{aligned}
& \mathrm{N}+\mathrm{O}_{2} \rightarrow \mathrm{NO}+\mathrm{O} \\
& \mathrm{N}+\mathrm{O}_{3} \rightarrow \mathrm{NO}+\mathrm{O}_{2}
\end{aligned}
$$

and $\mathrm{NO}_{2}$ is formed by the further reaction of $\mathrm{NO}$ :

$$
\mathrm{NO}+\mathrm{O}_{3} \rightarrow \mathrm{NO}_{2}+\mathrm{O}_{2}
$$

thus, different forms of nitrogen oxides are expected to form, only $\mathrm{NO}$ and $\mathrm{NO}_{2}$ where monitored.

Free electrons and negative ions formed in the inter-electrode space are accelerated towards the positive corona electrode by the electric field. In the proximity of the wire, named the corona plasma region, electrons are subtracted from gas molecules generating positive ions, which then migrate opposite the discharge electrode (Figure 1). Under the influence of an electric field, ions experience a force directing them toward the electrode that is charged oppositely to the charge on the ion.

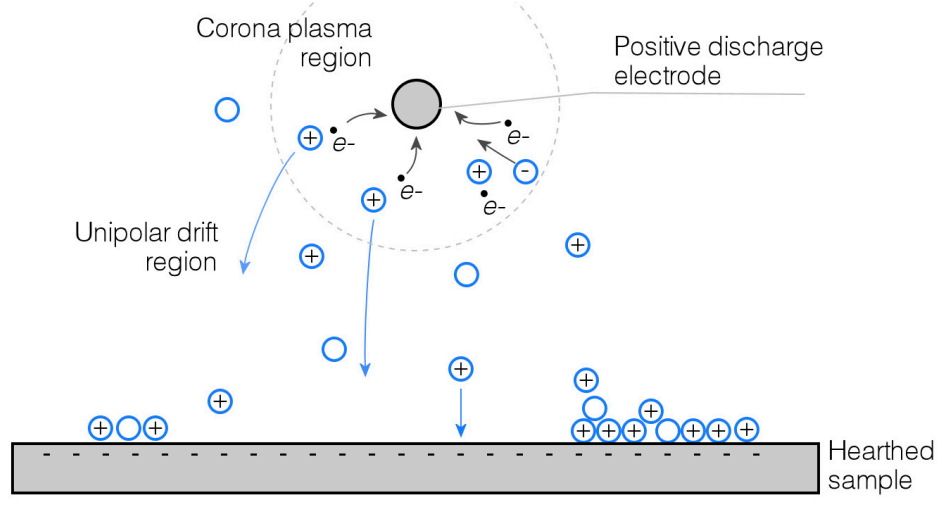

Figure 1. Model of a positive direct current (DC) corona discharge (not to scale).

Consider the following generic transport equation, where $N_{i}$ denotes the total flux of the i-charged species, $D_{i}$ represents the diffusivity, $u$ represents the velocity field, $z_{i}$ represents the charge number of the ion, $u_{i}$ represents the electrochemical mobility of the ion, $\phi$ is the electric potential (V), and $\nabla \phi$ represents the electric field [8].

$$
\boldsymbol{N}_{i}=-D_{i} \nabla c_{i}+c_{i} \boldsymbol{u}-z_{i} u_{i} c_{i} \nabla \phi
$$

The first contribution in Equation (1) is diffusive, which can be neglected because of the presence of the second advective term, representing the unidirectional flow induced by the fan. The third contribution describes the migration of the charged species under the external-applied electric field.

The aim of this study is to investigate the effect of an electric field applied to an adsorbent material in order to enhance the efficiency of gaseous organic pollutants removal. The test setup has been designed so that it can be representative of a modular process, easily implementable in pollution control technology.

\section{Materials and Methods}

The activated carbon cloth used is commercially available, provided by Purification Products Limited. Its characteristics are reported in Table 1. 
Table 1. Activated carbon fiber cloth characteristics.

\begin{tabular}{cc}
\hline \multicolumn{2}{c}{ Activated Carbon Cloth } \\
\hline Specific weight & $280 \mathrm{~g} / \mathrm{m}^{2}$ \\
Thickness & $13 \mathrm{~mm}$ \\
Average particle diameter & $352 \mu \mathrm{m}$ \\
Carbon content & $123 \mathrm{~g} / \mathrm{m}^{2}$ \\
Carbon BET surface area & $400 \mathrm{~m}^{2} / \mathrm{g}$ \\
Effective surface area & $40 \mathrm{~m}^{2} / \mathrm{g}$ \\
Available cloth surface area & $4920 \mathrm{~m}^{2} / \mathrm{m}^{2}$ \\
\hline
\end{tabular}

The determination of DC conductivity $\sigma$, was calculated by measuring the resistance $R$ and the dimensions of the conductor ( $l$, length and $S$, cross-sectional area) as follows:

$$
\sigma=\frac{l}{R S}
$$

The DC electrical conductivity, measured in room condition and averaged from four samples, is equal to $2.7 \pm 0.6 \mathrm{~S} / \mathrm{cm}$.

All of the organic compounds used (Acetone, Acetaldehyde, Benzene, Cyclohexane, Ethanol, Methyl Ethyl Ketone, Toluene, 1-Propanol) are of lab-grade purity and were purchased from Carlo Erba reagents S.A.S. These selected compounds have been chosen as representative for common organic pollutants.

The sample holder on which the specimens were placed is represented in Figure 2. A thin $(180 \mu \mathrm{m}$ diameter) tungsten wire electrode (discharge electrode) is set to positive polarity, whereas the opposite electrode (collector) is earthed trough two grounded connections at the ends of the activated carbon cloth sample. A fan, with trough apposite deflectors, induces an air flux quasi-parallel to the sample. The driving force of the electric field produces in all charged particles a vertical velocity component in the direction of the potential gradient.

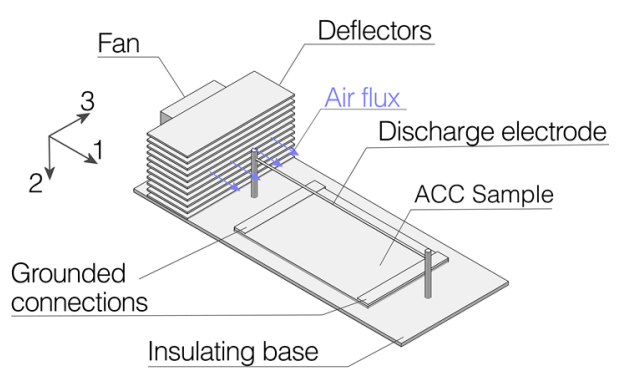

(a)

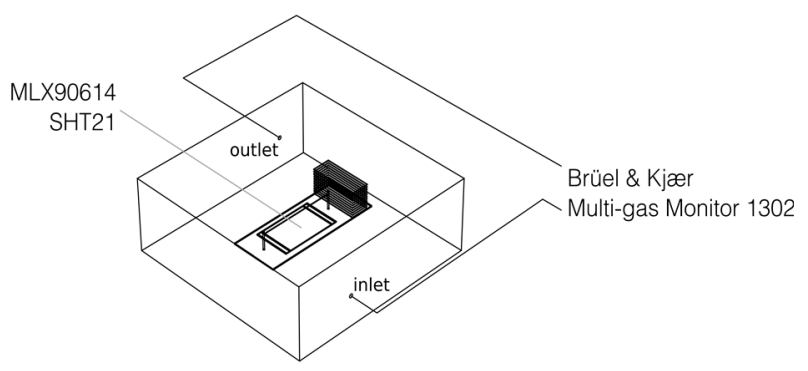

(b)

Figure 2. (a) reported a detail of the sample holder for the experimental setup. The air flux is parallel to 1 and the electric field induces an additional transport component in the 2 direction. (b), the full test apparatus is reported. The selected compound is injected between the outlet and the fan. Temperature and humidity sensors are placed under the activated carbon cloth (ACC) sample.

The sample holder is placed inside a $13 \mathrm{~L}$ glass box in which temperature and relative humidity are monitored (R.H. $\left.=59 \pm 6 \% \mathrm{~T}=24 \pm 2{ }^{\circ} \mathrm{C}\right)$ through a SHT21 $\left( \pm 0.3{ }^{\circ} \mathrm{C} \pm 2 \%\right)$ sensor. Sample temperature is also monitored by using a MLX90614 IR thermometer $\left( \pm 0.5^{\circ} \mathrm{C}\right)$ (Melexis NV, Ieper, Belgium). Air samples inside the box are collected and analyzed every $3 \mathrm{~min}$ by an automatic photoacoustic transducer system (Brüel and Kjaer Multi-gas Monitor Type 1302, Nærum, Denmark) equipped with UA0982, UA0984, UA0987, SB0527 filters. The initial amount of a determined organic 
compound injected into the test box is $33.5 \mathrm{mmol}$. Data collection starts $30 \mathrm{~s}$ after the initial injection, in order to account for its full vaporization.

To fit the experimental data, a pseudo-second order kinetic, as described by Ho [9], was adopted.

$$
\frac{t}{q_{t}}=\frac{1}{h}+\frac{1}{q_{e}} t
$$

where $\boldsymbol{q}_{e}$ is the amount of adsorbate $\left(\mathrm{mg} \mathrm{cm}^{-2}\right)$ at equilibrium, $\boldsymbol{q}_{t}$ is the amount of adsorbate $\left(\mathrm{mg} \mathrm{cm}^{-2}\right)$ at any time $t$, and $h$ is the initial adsorption rate $\left(\mathrm{mg} \mathrm{cm}^{-2} \mathrm{~min}^{-1}\right)$ as $q_{t} / t$ approaches 0 . In Equation (1), the pseudo-second-order model constants can be determined experimentally by plotting $\frac{t}{q_{t}}$ against $t$.

$\varepsilon$, the differential kinetic removal index accounts the different rate of adsorption with and without the application of the electric field. It is evaluated as follows:

$$
\varepsilon=\frac{h_{H V}-h_{a d s}}{h_{a d s}}
$$

To determine the amount of nitrites and nitrates adsorbed on the ACC, the sample is placed into an airtight container with approximately $40 \mathrm{~mL}$ of ultrapure water and subsequently mixed for $24 \mathrm{~h}$ on a suitable rotary shaker (Heidolph Reax 20, Schwabach, Germany), at a speed of $4 \mathrm{~min}^{-1}$. Then, the aqueous solution is analyzed through a liquid ion chromatography (IonPac Dionex AS23 Anion-Exchange Column, Waltham, MA, USA) in the first $3 \mathrm{~h}$ subsequent the extraction with water.

\section{Results}

\subsection{Removal Enhancement}

The differential kinetic removal index was plotted against the specific heat of fusion of selected organic compounds. Figure 3 demonstrates that:

- the kinetic of disappearance of the all organic compounds tested, under an external applied electric field, it is faster compared to the one in the absence of the electric field. This implies a positive $\varepsilon$, according Equation (3);

- a linear correlation fits the experimental data at different applied potentials;

- organic compounds having a low specific heat of fusion are more subject to such enhancement.

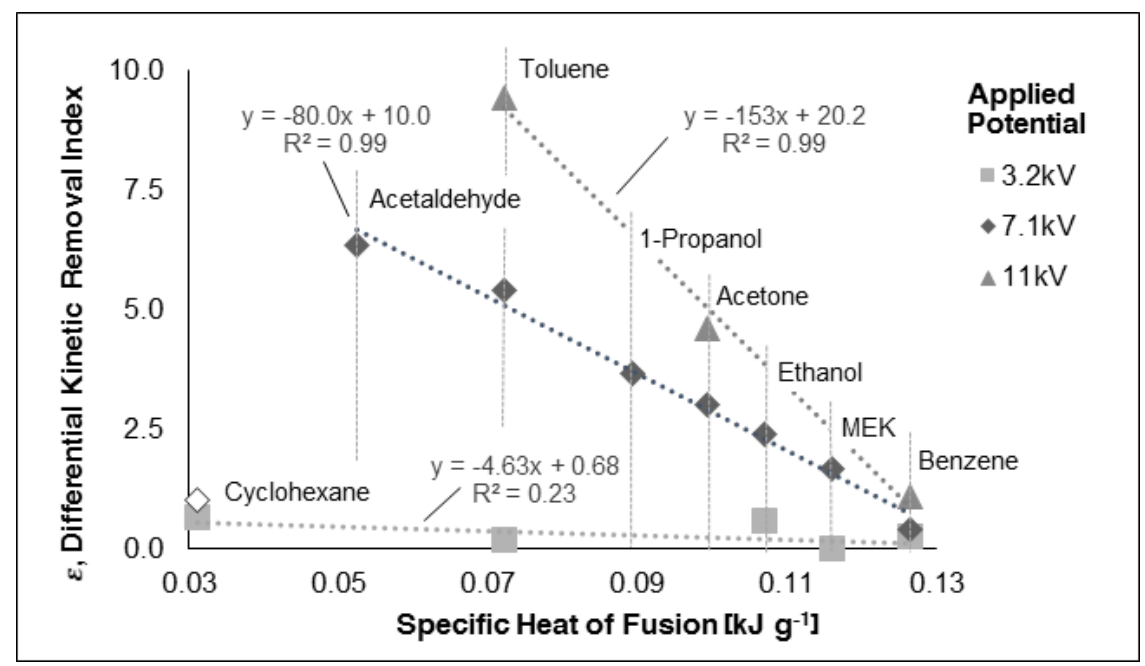

Figure 3. Plot of the differential kinetic removal index versus the specific heat of fusion of tested organic compounds. 
Considering a linear relation between the angular coefficient of the interpolant line and the applied potential, and by its substitution into the experimental relation found, the following interpolant function was determined and plotted in Figure 4.

$$
\varepsilon(\lambda, \Delta)=a \lambda \Delta+b \lambda+c \Delta+d
$$

where $\lambda$ is the specific heat of fusion, $\Delta$ is the applied potential and $a, b, c, d$ are experimental coefficients. Cyclohexane kinetic at $7.1 \mathrm{kV}$ was not included into the model. Fitted parameters are reported in Table 2.

Table 2. Fitted parameters for the Equation (4).

\begin{tabular}{cc}
\hline Coefficients & Fitted Value \\
\hline$a$ & -19.31 \\
$b$ & 57.36 \\
$c$ & 2.544 \\
$d$ & -7.394 \\
Goodness of fit & 1.336 \\
SSE * & 0.9883 \\
R-square & 0.9854 \\
Adjusted R-square & 0.3337 \\
RMSE $\$$ &
\end{tabular}

* The sum of squares due to error (SSE); ${ }^{\circledR}$ Root mean squared error (RMSE).

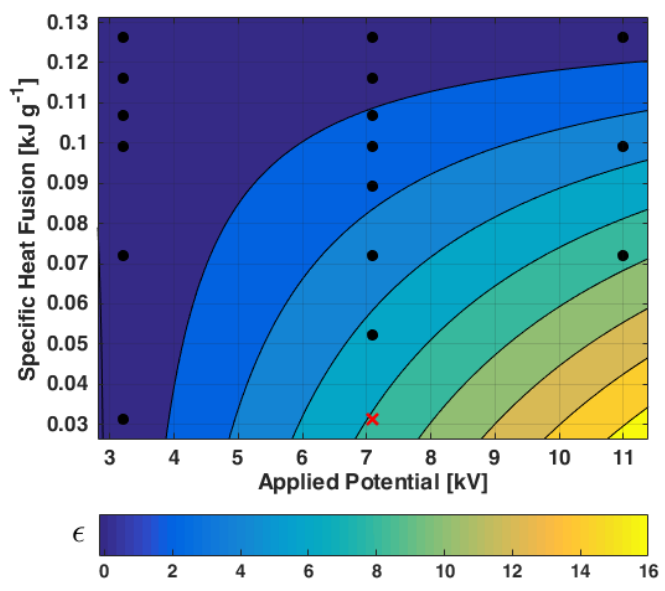

(a)

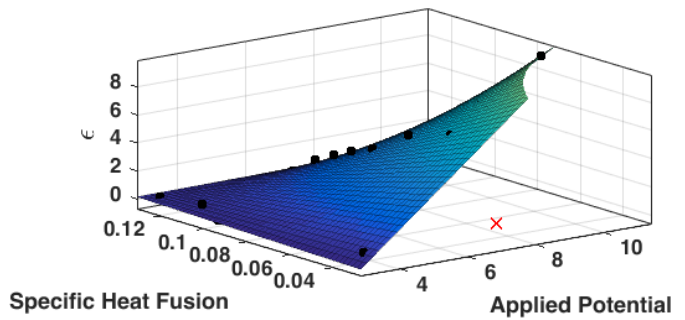

(b)

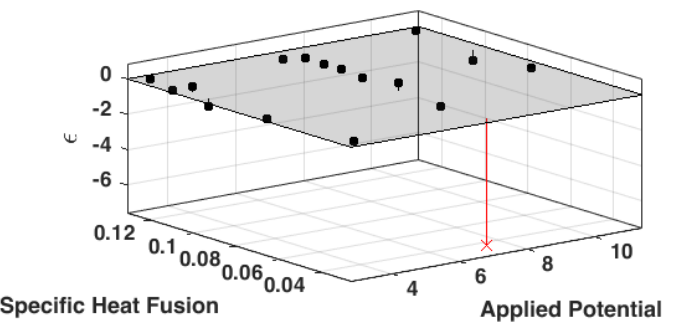

(c)

Figure 4. Fitted model; contour plot (a), main plot (b), residuals plot (c).

\subsection{Subsequent Adsorption Tests}

In this test, the same amount of Methyl Ethyl Ketone (MEK, $30 \mu \mathrm{L}$ ) was injected inside the box every $60 \mathrm{~min}$ for $7 \mathrm{~h}$. Collected data was treated as previously described. Results are reported in Figure 5. Fitted parameters show:

- the adsorption rate under the electric field initially doubled the one without the electric field, decreases in subsequent tests (a);

- the amount of adsorbate decreases slightly faster at $60 \mathrm{~min}$ into the test in the presence of the electric field (b). 


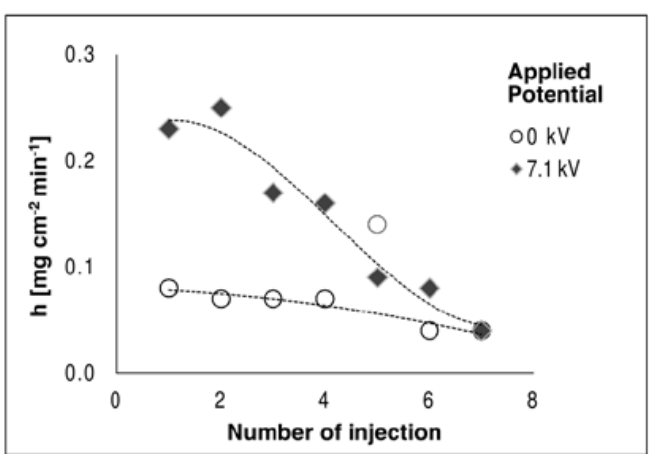

(a)

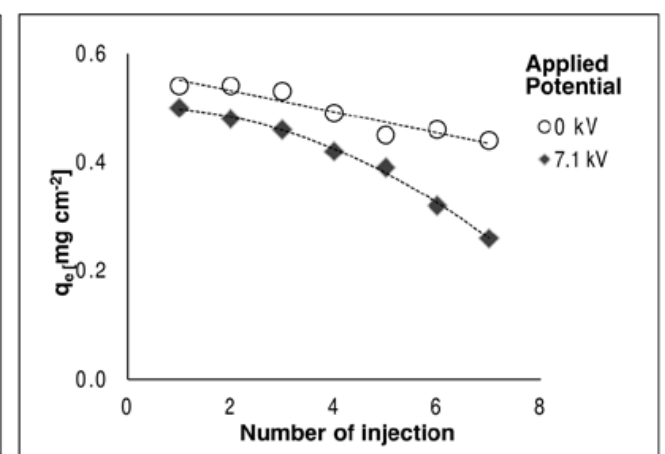

(b)

Figure 5. Variation of the adsorption parameter for subsequent injection of MEK: (a) $h$, initial adsorption rate and (b) $q_{e}$, amount of adsorbate at $t=60 \mathrm{~min}$ with and without the application of an external electric field.

\section{3. $\mathrm{O}_{3}, \mathrm{NO}_{2}$ and Nitrates}

Additionally, accumulated nitrites and nitrates over the adsorptive sample were quantified. Table 3 shows the amounts of nitrogen as nitrites and nitrates accumulated on the adsorptive sample, resulting from the analysis of the sample leaching liquor, and the amount of nitrogen dioxide and ozone generated during the test at various electrical potentials applied.

Table 3. Nitrites and nitrates determined in the ACC extraction liquor, and $\mathrm{NO}_{2}$ and $\mathrm{O}_{3}$ generated in the air during $90 \mathrm{~min}$ of testing.

\begin{tabular}{cccccc}
\hline \multirow{2}{*}{ Applied Voltage } & \multicolumn{3}{c}{ Extracted Liquor } & \multicolumn{3}{c}{ Air } \\
\cline { 2 - 6 } $\mathbf{k V}$ & $\begin{array}{c}\mathbf{N O}^{2-} \\
\boldsymbol{\mu m o l}\end{array}$ & $\begin{array}{c}\mathbf{N O}^{3-} \\
\boldsymbol{\mu m o l}\end{array}$ & $\begin{array}{c}\mathbf{N} \text { Tot } \\
\boldsymbol{\mu m o l}\end{array}$ & $\begin{array}{c}\mathbf{N O}_{2} \\
\boldsymbol{\mu m o l}\end{array}$ & $\begin{array}{c}\mathbf{O}_{3} \\
\boldsymbol{m} \mathbf{m o l}\end{array}$ \\
\hline 0 & 0.00 & 0.00 & 0.00 & 0.02 & 0.00 \\
3.2 & 0.00 & 0.02 & 0.00 & 0.02 & 0.01 \\
7.1 & 0.25 & 0.24 & 0.13 & 0.14 & 0.07 \\
11 & 0.69 & 0.17 & 0.25 & 0.35 & 0.41 \\
\hline
\end{tabular}

By increasing the electrical potential applied, the concentrations of ozone and nitrogen dioxide generated within the test box increased jointly with the level of nitrites and nitrates found in the leaching ACC sample liquor.

\section{Discussion}

The enhanced disappearance rate of selected organic compounds can be explained (i) by the generation of reactive oxidative species $\left({ }^{\circ} \mathrm{OH}\right.$ radical and hydrogen peroxide), who take part in the degradation of such compounds [10,11], (ii) by the modification of the sorbent surface [5,12], and (iii) by the electric polarization of the compounds $[13,14]$.

The decomposition of several VOCs in presence of a positive DC streamer discharge was studied by $\mathrm{Li}$ et al. [15]. However, $\mathrm{CO}$ and $\mathrm{CO}_{2}$ concentrations were monitored during all tests and did not show any significant increase. For those reasons, it is unlikely that a complete VOC mineralization can occur.

Kodama [12] and Lee [6] both highlighted the role of oxygen in plasma, which creates oxygen radicals that react on the surface of activated carbon, resulting in the creation of weakly acidic functional groups. In our study, the acidification of the adsorbent material is justified by the presence of nitrites and nitrates on the activated carbon, resulting from the dissociation of nitric and nitrous acids. The higher concentration of nitrites compared to nitrates can be related to the carbonaceous 
nature of the adsorbent material [16]. The accumulation of nitrites and nitrates on the sample can also explain the decrease in the amount of MEK adsorbed at $t=60$ min under subsequent testing (Figure $3 b$ ), due a faster depletion of the active sites.

The presence of dielectric air between the positively charged corona and the grounded collector plate, where the ACC is placed, results in the formation of a negative charge on the surface of the ACC due to the electrostatic induction. Moreover, the effect of the strong electric field induced by the discharge electrode leads to a deformation in the molecule (i.e., a local displacement of the molecular charge), known as molecular polarizability [17], which is proportional to the intensity of the local field. For this reason, some authors linked the increased activity in VOC removal with the ionization potential [3], or with the hydrogen weight fraction of the compound [18].

In our study, an interesting correlation was found by plotting the kinetic increase along the specific heat of fusion. Another correlation was also found with the chemical hardness [19], but it was not presented in this paper due to the lack of experimental values.

Physical adsorption is known to be intrinsically weak and to be characterized by relatively small heats of adsorption, close to the enthalpy of liquefaction of the adsorptive material, and typically comprised in the $5-45 \mathrm{~kJ} \mathrm{~mol}^{-1}$ range [20] since it is essentially a condensation process analogous to liquefaction on the absorbent material. Indeed, the number of degrees of freedom possessed by the adsorbed species is less than one prior to adsorption, because the entropy of the absorbent material is unaltered since no chemical reaction occurs. Our results suggest that VOCs with lower heat of fusion are more favored by the electric field, as reported in Figure 2, because of a stronger electrical-induced dipole.

\section{Conclusions}

The objective of this study was to highlight a synergistic aspect between two widely known technologies, in order to propose a new hybrid process in the field of pollution control technologies [1].

The application of an external electric field, by a thin wire (having a potential ranging between 3.2 and $11 \mathrm{kV}$ ) on a grounded activated carbon cloth, showed an increased disappearance rate of selected organic compounds.

Electrostatic precipitation is a widely known and adopted technology for the removal of fine particles, which are charged by ions generated by the electric field and accumulated on the collector electrode. Its implementation with a proper adsorbent material, as an ACC, can also synergistically enhance the removal of other gaseous pollutants.

This enhancement is a function of the applied potential and of the organic compound; in particular, a good correlation with the specific heat of fusion was found and a correlation with the chemical hardness was suggested. These experimental results suggest that, in the interaction between the adsorbate and adsorbent materials, the first may be more affected to the applied electric field effect.

Micro-discharges over the electrode surface generates active species which can react with the organic compounds or which can modify the surface of the adsorbent material. The formation of ozone may be limited by lowering the applied potential or by increasing the affinity with the ACC. However, ozone can have a beneficial effect on activated carbon by enhancing the ozone transformation into $\cdot \mathrm{OH}$ radicals [21], and to create more acid sites on the surface [5,12]. The accumulation of nitrites and nitrates on the activated carbon by $\mathrm{NO}_{2}$ production can limit its adsorptive capacity. However, experimental results show that the kinetics of adsorption can be increased up to 10-fold under electric field.

Further studies are intended to pursue the optimization of this process by choosing different adsorbent materials, and to gain a better understanding of the nature of such an enhancement by using different gases instead of air.

Author Contributions: Mattia Pierpaoli and Gabriele Fava conceived and designed the experiments; Mattia Pierpaoli performed the experiments and analyzed the data; Maria Letizia Ruello, Gabriele Fava supervised the work and discussed the results.

Conflicts of Interest: The authors declare no conflict of interest. 


\section{References}

1. Pierpaoli, M.; Giosuè, C.; Ruello, M.L.; Fava, G. Appraisal of a hybrid air cleaning process. Environ. Sci. Pollut. Res. 2016, 1-8. [CrossRef]

2. Raju, B.R.; Reddy, E.L.; Karuppiah, J.; Reddy, P.M.K.; Subrahmanyam, C. Catalytic non-thermal plasma reactor for the decomposition of a mixture. J. Chem. Sci. 2013, 125, 673-678. [CrossRef]

3. Nunez, C.M.; Ramsey, G.H.; Ponder, W.H.; Abbott, J.H.; Hamel, L.E.; Kariher, P.H. Corona destruction: An innovative control technology for VOCs and air toxics. J. Air Waste Manag. Assoc. 1993, 43, 242-247. [CrossRef]

4. Chen, J.; Davidson, J.H. Ozone production in the positive DC corona discharge: Model and comparison to experiments. Plasma Chem. Plasma Process. 2002, 22, 495-522. [CrossRef]

5. Lee, D.; Hong, S.H.; Paek, K.H.; Ju, W.T. Adsorbability enhancement of activated carbon by dielectric barrier discharge plasma treatment. Surf. Coat. Technol. 2005, 200, 2277-2282. [CrossRef]

6. Kogelschatz, U. Dielectric-barrier discharges: Their history, discharge physics, and industrial applications. Plasma Chem. Plasma Process. 2003, 23, 1-46. [CrossRef]

7. Peek, F.W. Dielectric Phenomena in High Voltage Engineering; McGraw-Hill Book Company: New York, NY, USA, 1920.

8. Bockris, J.O.; Reddy, A.K.N. Modern Electrochemistry; Springer: New York, NY, USA, 2001.

9. Ho, Y.S.; McKay, G. Pseudo-second order model for sorption processes. Process Biochem. 1999, 34, 451-465. [CrossRef]

10. Klamt, A. Estimation of gas-phase hydroxyl radical rate constants of oxygenated compounds based on molecular orbital calculations. Chemosphere 1996, 32, 717-726. [CrossRef]

11. Ohshima, T.; Kondo, T.; Kitajima, N.; Sato, M. Adsorption and plasma decomposition of gaseous acetaldehyde on fibrous activated carbon. IEEE Trans. Ind. Appl. 2010, 46, 23-28. [CrossRef]

12. Kodama, S.; Habaki, H.; Sekiguchi, H.; Kawasaki, J. Surface modification of adsorbents by dielectric barrier discharge. Thin Solid Films 2002, 407, 151-155. [CrossRef]

13. Han, Y.; Quan, X.; Chen, S.; Zhao, H.; Cui, C.; Zhao, Y. Electrochemically enhanced adsorption of aniline on activated carbon fibers. Sep. Purif. Technol. 2006, 50, 365-372. [CrossRef]

14. Han, Y.; Quan, X.; Zhao, H.; Chen, S.; Zhao, Y. Kinetics of enhanced adsorption by polarization for organic pollutants on activated carbon fiber. Front. Environ. Sci. Eng. 2007, 1, 83-88. [CrossRef]

15. Li, J.; Zhu, T.; Xing, F.; He, W. Decomposition of dilute VOCs in air by a streamer discharge. Int. J. Plasma Environ. Sci. Technol, 2007, 1, 141-145.

16. Gundel, L.A.; Guyot-Sionnest, N.S.; Novakov, T. A study of the interaction of $\mathrm{NO}_{2}$ with carbon particles. Aerosol Sci. Technol. 1989, 10. [CrossRef]

17. Meurant, G. Theory of Electric Polarization; Elsevier: Amsterdam, The Netherlands, 2012.

18. Karatum, O.; Deshusses, M.A. A comparative study of dilute VOCs treatment in a non-thermal plasma reactor. Chem. Eng. J. 2016, 294, 308-315. [CrossRef]

19. Parr, R.G.; Pearson, R.G. Absolute hardness: Companion parameter to absolute electronegativity. J. Am. Chem. Soc. 1983, 105, 7512-7516. [CrossRef]

20. Bolis, V. Fundamentals in adsorption at the solid-gas interface. Concepts and thermodynamics. In Calorimetry and Thermal Methods in Catalysis; Springer: Berlin/Heidelberg, Germany, 2013.

21. Sánchez-Polo, M.; Salhi, E.; Rivera-Utrilla, J.; Von Gunten, U. Combination of ozone with activated carbon as an alternative to conventional advanced oxidation processes. Ozone Sci. Eng. 2006, 28, 237-245. [CrossRef]

(C) 2017 by the authors. Licensee MDPI, Basel, Switzerland. This article is an open access article distributed under the terms and conditions of the Creative Commons Attribution (CC BY) license (http:/ / creativecommons.org/licenses/by/4.0/). 